\title{
Hubungan antara intensitas kebisingan dan tekanan darah pada pekerja PT X
}

\author{
Christopher Adhisasmita Yandoyo ${ }^{1}$ Lie Tanu Merijanti ${ }^{2}$
}

\begin{abstract}
ABSTRAK
\section{LATAR BELAKANG}

Tekanan darah tinggi atau hipertensi merupakan suatu kondisi yang mungkin tidak disadari oleh banyak orang namun menjadi faktor resiko independen untuk penyakit jantung, ginjal, pembuluh darah, mata, otak dan lain-lain. Akibat dari tekanan darah tinggi, aliran darah menjadi abnormal sehingga dapat merusak struktur organ-organ tersebut. Berbagai penelitian telah menunjukkan bahwa tekanan darah dapat dipengaruhi oleh pajanan dari perubahan fisika dan kimia lingkungan hidup. Salah satu pajanan pada lingkungan hidup yang dapat mempengaruhi tekanan darah adalah kebisingan. Untuk lebih memahami apakah terdapat pengaruh perubahan fisika dan kimia terhadap tekanan darah, maka perlu dilakukan penelitian tentang intensitas kebisingan sebagai parameter perubahan fisika tersebut pada pajanan bising kronis konstan di sebuah perusahaan.
\end{abstract}

\section{METODE}

Penelitian menggunakan studi observasional dengan desain potong lintang yang mengikutsertakan 62 tenaga kerja bagian produksi PT. $\mathrm{X}$. Data dikumpulkan dengan menggunakan kuesioner yang meliputi usia, jenis kelamin, lama bekerja, Body Mass Index (BMI)Asia Pasifik, konsumsi rokok, konsumsi kafein, riwayat hipertensi keluarga, riwayat hipertensi diri, riwayat pengobatan hipertensi. Pengukuran intensitas bising menggunakan noise level meter dan pengukuran tekanan darah menggunakan sphygmomanometer air raksa. Analisis data menggunakan uji Fisher Exact dengan tingkat kemaknaan (p) 0.05.

\section{HASIL}

Analisis hubungan antar variabel menunjukkan adanya hubungan antara intensitas kebisingan dengan tekanan darah $(\mathrm{p}=0.002)$.

\section{KESIMPULAN}

Penelitian menunjukkan adanya hubungan antara intensitas kebisingan dengan peningkatan tekanan darah.

Kata kunci : intensitas kebisingan, tekanan darah, hipertensi, kesehatan kerja
${ }^{1}$ Program Studi Kedokteran,

Fakultas Kedokteran, Universitas Trisakti

2 Departemen Ilmu Kesehatan

Kerja,

Fakultas Kedokteran,

Universitas Trisakti

\section{Korespondensi:}

Lie Tanu Merijanti

Departemen Ilmu Kesehatan Kerja, Fakultas Kedokteran,

Universitas Trisakti, Jalan Kyai

Tapa No. 260, Grogol, Jakarta Barat

Email: liemerijanti@trisakti.ac.id

J Biomedika Kesehat 2019;2(1):10-14 DOI: 10.18051/JBiomedKes.2019.

v2.10-14

pISSN: 2621-539X / eISSN: 2621-5470

Artikel akses terbuka (open access) ini didistribusikan di bawah lisensi Creative Commons Attribution 4.0 International (CC-BY 4.0) 


\section{ABSTRACT}

\section{Correlation between noise intensity and blood pressure at X Limited (Ltd.) Company}

\section{BACKGROUND}

High blood pressure or hypertension is an unwitting condition that actually is a major risk factor of developing some chronic disease such as heart disease, kidney disease, vascular disease, eye and brain damage. Abnormal blood pressure can damage the vascular system resulting in damage of the organs. Some studies show that blood pressure can be intervened by changes in physical and chemical environment. One environment that disrupts the cardiovascular system, for example noise. The purpose of this study was to determine the effect of chronic noise exposure on changes in blood pressure in factory workers.

\section{METHODS}

A Cross-sectional observational study was conducted and a total of 62 workers in production division in X Limited (Ltd.) Company. Data was collected by questionnaires covering on age, sex, years of working, body mass index (BMI) Asia Pacific classification, ciggarate consumtion, caffeine consumtion, familial hypertension history, self hypertension history, self medication of hypertension history. Noise intensity was measured by using (noise level meter) and blood pressure was measured using sphygmomanometer. Data were then analysed using Fisher Exact Test with significance $(\mathrm{p}) 0.05$.

\section{RESULT}

There was an assosiation between noise intensity and blood pressure $(p=0.002)$.

\section{CONCLUSION}

The study revealed an assosiation between noise intensity and the increase of blood pressure level.

Keywords : noise intensity, blood pressure, hypertension, occupational health

\section{PENDAHULUAN}

Hipertensi merupakan salah satu manifestasi gangguan keseimbangan hemodinamik yang mengakibatkan berbagai macam komplikasi kardiovaskular dan berbagai sistem lain dalam tubuh. Hasil riset kesehatan dasar (Riskesdas) tahun 2018 memperlihatkan bahwa prevalensi hipertensi pada orang Indonesia dewasa yang berumur $\geq 18$ tahun sebesar $34.1 \%$. Jika dibandingkan dengan data Riskesdas tahun 2015, jumlah tersebut meningkat $8.3 \%$. Bukan hanya di Indonesia, hipertensi menjadi penting karena menyumbang sekitar $60 \%$ dari kematian di seluruh dunia. ${ }^{(1)}$

Penyebab hipertensi bersifat multifaktorial antara lain faktor genetik, ras, sosio budaya, gaya hidup dan juga faktor lingkungan kerja di mana salah satunya adalah kebisingan. ${ }^{(1,2)}$ Kebisingan merupakan salah satu masalah industri dan dapat menimbulkan gangguan terhadap kesehatan pekerja seperti gangguan pendengaran, hipertensi, penyakit jantung iskemik, diabetes, gangguan tidur dan performa kerja. ${ }^{(2-6)}$ Intensitas kebisingan, frekuensi kebisingan, dan lamanya terpajan bising di tempat kerja adalah faktor yang menentukan dampak gangguan kesehatan yang ditimbulkannya.

Beberapa penelitian menunjukkan hasil yang berbeda mengenai hubungan antara kebisingan dan tekanan darah. ${ }^{(2-7)}$ Penelitian pada 361 pekerja pelabuhan di Tarakan Kalimantan mendapatkan prevalensi hipertensi sebesar $21.88 \%$ dan kebisingan berhubungan dengan kejadian hipertensi. (2) Hasil penelitian oleh Sherman et al memperlihatkan perbedaan hasil, yaitu tidak menemukan adanya kenaikan insidens hipertensi pada pekerja industri yang terpajan bising.(7) Tujuan penelitian ini untuk mengetahui hubungan antara kebisingan dengan kejadian hipertensi pada karyawan bagian produksi PT X.

\section{METODE}

Penelitian ini merupakan studi potong lintang (cross-sectional) yang melibatkan pada 62 responden bagian produksi PT X yaitu salah satu pabrik plastik di daerah Jawa Tengah, Indonesia. Pemilihan sampel secara stratified random sampling, dengan penarikan sampel secara acak pada pekerja tiap bagian produksi di PT X. Estimasi besar sampel yang dibutuhkan adalah 62 subjek. Semua subjek yang diikutsertakan diambit harus memenuhi kriteria inklusi dan eksklusi yang telah ditetapkan peneliti. Kriteria inklusi adalah pekerja bagian produksi karung PT X dan telah bekerja $\geq 5$ tahun. Kriteria eksklusi yaitu riwayat keturunan hipertensi, diagnosis hipertensi dalam 5 tahun terakhir, dalam terapi hipertensi, obesitas (body mass index $=\mathrm{BMI}>25$ Asia Pasifik), ${ }^{(8)}$ kebiasaan merokok dan konsumsi kafein. 
Pengukuran intensitas kebisingan dilakukan dengan menggunakan digital sound level meter dengan merek Krisbow KW062914 in 1 Environment Meter. Tekanan darah diukur memakai sphygmomanometer air raksa (Riester, Rudolf Riester $\mathrm{GmbH}$, Jerman). Klasifikasi tekanan darah berdasarkan JNC (Joint National Committee on hypertension) VIII. ${ }^{(9)}$ Data univariat berupa karakteristik responden (usia, jenis kelamin, pendidikan, BMI, tekanan darah (sistolik dan diastolik) dan karakteristik pekerjaan (lama bekerja, lama kerja, unit kerja, intensitas kebisingan) disajikan dalam bentuk persentase pada tabel distribusi frekuensi. Analisis bivariat antara kebisingan dan klasifikasi hipertensi menggunakan uji Fisher Exact dengan tingkat kemaknaan (p) $<0.05$. Persetujuan etik telah dikeluarkan dan disetujui oleh Komite Etik Fakultas Kedokteran Universitas Trisakti.

\section{HASIL}

Karakteristik responden dan pekerjaan disajikan pada Tabel 1. Unit Kerja yang terdapat pada bagian produksi PT. X terbagi menjadi 3 gedung ( $\mathrm{A}, \mathrm{B}$ dan $\mathrm{E})$ di mana setiap gedung terdapat unit fungsional pelaksana produksi yang terbagi menjadi 3 tahapan produksi yang mencakup extruder, circular loom dan finishing. Waktu kerja terbagi dalam 3 shift yaitu shift 1 (07.00-16.00), shift 2 (16.00-23.00), dan shift 3 (23.00-07.00). Pekerja bagian produksi didominasi oleh wanita (74.2\%), sebagian besar berusia antara 30-39 tahun, berpendidikan sekolah menengah tingkat atas/kejuruan. Penelitian oleh Bodin mendapatkan bahwa intensitas bising $>64 \mathrm{~dB}$ pada kelompok umur 40-59 tahun. ${ }^{(10)}$

Intensitas kebisingan terendah pada penelitian ini dijumpai pada unit Finishing A dengan $81.0 \mathrm{~dB}$ dan tertinggi $100.4 \mathrm{~dB}$ pada unit Circular Loom B, terdapat 53 responden (85.5\%) dengan pajanan kebisingan melebihi nilai ambang kebisingan/8jam/hari $(\leq 85 \mathrm{~dB})$, dan didapatkan 18 pekerja dengan tekanan darah normal, 24 pekerja prehipertensi dan $20(32.2 \%)$ pekerja mengalami hipertensi. Untuk mengetahui hubungan antara intensitas kebisingan dan hipertensi, maka dilakukan uji Fisher yang dapat dilihat pada Tabel 2.
Tabel 1. Distribusi frekuensi karakteristik responden dan pekerjaan

\begin{tabular}{|c|c|c|}
\hline Variabel & $\begin{array}{c}\text { Jumlah } \\
(\mathrm{n}=62)\end{array}$ & $\begin{array}{c}\text { Persentase } \\
(\%)\end{array}$ \\
\hline \multicolumn{3}{|l|}{ Jenis Kelamin } \\
\hline Laki-Laki & 16 & 25.8 \\
\hline Perempuan & 46 & 74.2 \\
\hline \multicolumn{3}{|l|}{ Klasifikasi Umur (tahun) } \\
\hline$<30$ & 13 & 21 \\
\hline $30-39$ & 40 & 64.5 \\
\hline$\geq 40$ & 9 & 14.5 \\
\hline \multicolumn{3}{|l|}{ Pendidikan } \\
\hline SMP & 4 & 6.5 \\
\hline SMA/SMK & 58 & 93.5 \\
\hline \multicolumn{3}{|l|}{ Waktu Kerja } \\
\hline Shift 1 & 16 & 25.8 \\
\hline Shift 2 & 16 & 25.8 \\
\hline Shift 3 & 30 & 48.4 \\
\hline \multicolumn{3}{|l|}{ Unit Kerja } \\
\hline Extruder B & 9 & 14.5 \\
\hline Circular Loom B & 17 & 27.4 \\
\hline Circular Loom A & 3 & 4.8 \\
\hline Finishing A & 9 & 14.5 \\
\hline Extruder E & 2 & 3.2 \\
\hline Circular Loom E & 13 & 21.0 \\
\hline Finishing E & 9 & 14.5 \\
\hline \multicolumn{3}{|l|}{ Klasifikasi BMI } \\
\hline Underweight & 8 & 12.9 \\
\hline Normal & 38 & 61.3 \\
\hline Overweight & 16 & 25.8 \\
\hline \multicolumn{3}{|l|}{ Klasifikasi Tekanan Darah } \\
\hline Normal & 18 & 29.0 \\
\hline Pra-Hipertensi & 24 & 38.7 \\
\hline Hipertensi Tahap 1 & 17 & 27.4 \\
\hline Hipertensi Tahap 2 & 3 & 4.8 \\
\hline \multicolumn{3}{|c|}{ Intensitas Kebisingan (dB) } \\
\hline 81.0 (Finishing A) & 9 & 14.5 \\
\hline 92.2 (Finishing E) & 9 & 14.5 \\
\hline 93.7 (Extruder B dan E) & 11 & 17.7 \\
\hline 95.1 (Circular Loom A) & 3 & 4.8 \\
\hline 95.6 (Circular Loom E) & 13 & 21.0 \\
\hline 100.4 (Circular Loom B) & 17 & 27.4 \\
\hline \multicolumn{3}{|l|}{ Nilai Ambang Batas } \\
\hline Kebisingan/8Jam/Hari & & \\
\hline Normal & $\begin{array}{c}9 \\
53\end{array}$ & $\begin{array}{l}14.5 \\
85.5\end{array}$ \\
\hline Melebihi & 53 & 85.5 \\
\hline \multicolumn{3}{|c|}{$\begin{array}{l}\text { Keterangan: } \mathrm{n}=\text { jumlah responden, } \%=\text { persen, } \\
\mathrm{SMP}=\text { sekolah menengah pertama, } \mathrm{SMK}=\text { sekolah } \\
\text { menengah kejuruan, } \mathrm{BMI}=\text { body mass index } ; \mathrm{dB}=\mathrm{dec}\end{array}$} \\
\hline Bell. & & \\
\hline
\end{tabular}

Dari Tabel 2, dapat disimpulkan bahwa terdapat hubungan bermakna $(p=0.002)$ antara kebisingan dan tekanan darah.

Dari hasil uji Fisher Exact, ditemukan hubungan antara intensitas kebisingan dengan tekanan darah $(p=0.002)$. Hal ini menunjukkan bahwa intensitas kebisingan yang melebihi nilai ambang batas yang telah ditentukan dalam jangka waktu tertentu dapat meningkatkan tekanan darah seseorang. 


\section{PEMBAHASAN}

Penelitian Chang et al yang melakukan studi kohort selama 10 tahun pada tenaga kerja pria pabrik pembuatan pesawat di Taiwan menemukan rata-rata peningkatan tekanan darah sistolik dan diastolik setelah subjek diikuti selama 10 tahun dan menemukan bahwa dalam 10 tahun subjek yang terpajan intensitas suara $\geq 85 \mathrm{dBA}$ memiliki resiko hipertensi 1.93 kali lebih besar dari tenaga kerja yang terpajan intensitas suara $\leq 85$ dBA. ${ }^{(11)}$ Penelitian dengan hasil serupa yaitu peningkatan tekanan darah dan denyut nadi juga ditemukan oleh Kalantary et al, yang melakukan studi kasus-kontrol pada tenaga kerja pada industri pembuatan suku cadang kendaraan bermotor di Teheran, Iran. ${ }^{(12)}$ Sebuah meta-analisis oleh Tomei et al yang menganalisis 15.658 tenaga kerja memberikan hasil bahwa semakin tinggi pajanan intensitas kebisingan, maka semakin tinggi juga peningkatan tekanan darah sistolik, tekanan darah diastolik, frekuensi nadi dan abnormalitas Elektrokardiografi (EKG). ${ }^{(13)}$

Kebisingan selain dapat mengganggu fungsi pendengaran, juga menyebabkan gangguan kesehatan lain seperti gangguan tidur, penurunan peforma, gangguan sistem kardiovaskular, dan gangguan psikis. ${ }^{(5,14,15)}$ Sampai saat ini mekanisme terjadinya perubahan dalam hal peningkatan tekanan darah yang disebabkan oleh pajanan kebisingan masih belum pasti. Beberapa teori seperti ketidakseimbangan hormon dan peningkatan respon simpatis menjadi alasan dasar bagaimana mekanisme kenaikan tekanan darah dapat terjadi. ${ }^{(16)}$

Pada pajanan bising kronik dan melebihi nilai ambang batas yang ditentukan, maka sistem kardiovaskular tidak mengalami adaptasi yang serupa dengan adaptasi tubuh lain terhadap berbagai stress jenis lain, seperti penyesuaian tubuh untuk pengaturuan suhu terhadap lingkungan sekitar yang terlalu dingin atau panas dan tetap mengalami aktivasi saraf simpatis. Perubahan lain adalah tahap tidur yang dalam menuju tidur yang dangkal akibat respon terhadap kebisingan. Respon pertama tubuh terhadap kebisingan adalah aktivasi dari saraf simpatis, serupa saat persiapan tubuh bangun di pagi hari. Meskipun tekanan darah normalnya menurun selama tidur, manusia mengalami gangguan terhadap bising itu sendiri dan mengalami kesulitan mencapai titik nadir pada saat tidur dikarenakan tekanan darah dan nadi meningkat serupa peningkatan respon simpatis akibat bising. (17) Berkurangnya kualitas dan lama waktu tidur meningkatkan ketegangan kardiovaskular yang bermanifestasi pada peningkatan tekanan darah dan gangguan irama sirkardian. ${ }^{(18)}$ Gangguan tidur juga berhubungan dengan peningkatan hormon stress. ${ }^{(18,19)} \quad$ Kesiagaan/arousal berhubungan dengan peningkatan lipid dan tingkat kortisol, dan merupakan alur yang sama dengan gangguan tidur. Peningkatan lemak darah, denyut jantung, tekanan darah dan stress dapat menyebabkan aterosklerosis yang merupakan penyebab penyakit jantung. ${ }^{20}$

Dalam pelaksanaan penelitian ini, terdapat beberapa keterbatasan yang dapat memberikan pengaruh hasil penelitian yang telah dibahas. Belum terstandardisasinya kuesioner mungkin dapat mempengaruhi responden dalam memenuhi kriteria inklusi dan eksklusi. Penelitian ini menggunakan jenis penelitian potong lintang sehingga tidak dapat mengetahui hubungan sebab akibat secara jelas faktor-faktor apakah yang sebenarnya mempengaruhi tekanan darah pada subjek. Kami berharap agar kedepan dapat dilakukan penelitian lanjutan dengan desain penelitian kohort ataupun kasus kontrol, dengan mengukur kadar hormone, tingkat stress dan aktivitas sistem saraf simpatis. Hal tersebut perlu

Tabel 2. Intensitas kebisingan dan tekanan darah

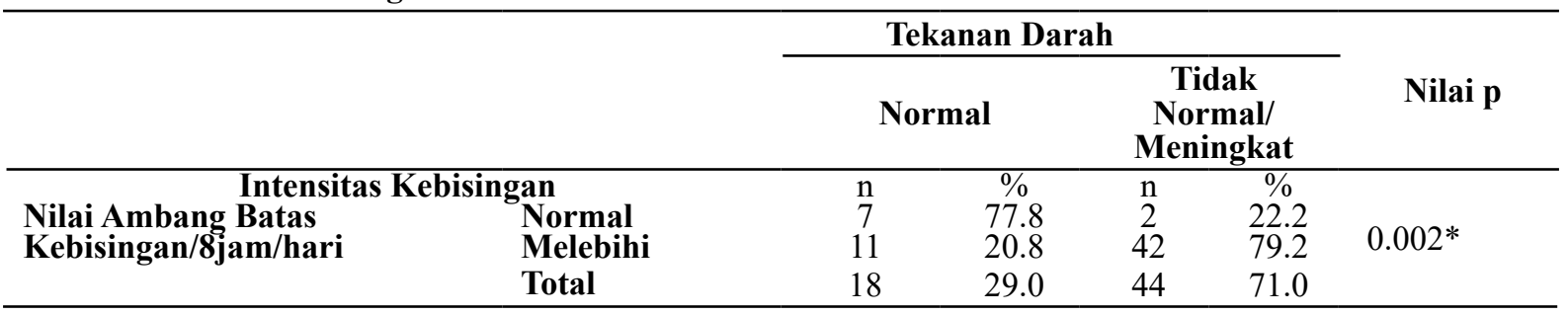

$\mathrm{n}=$ jumlah; $\%=$ persentase; $*=$ uji Fisher 
dilakukan untuk mengetahui hubungan jangka panjang maupun menentukan kemungkinan faktor resiko maupun mekanisme secara jelas hubungan antara intensitas kebisingan dan tekanan darah.

\section{KESIMPULAN}

Terdapat hubungan yang bermakna antara intensitas kebisingan dengan tekanan darah pada tenaga kerja bagian produksi PT. X.

\section{KONFLIK KEPENTINGAN}

Penulis menyatakan tidak ada konflik kepentingan.

\section{DAFTAR REFERENSI}

1. Riset Kesehatan Dasar 2018. Badan Penelitian dan Pengembangan Kesehatan Kementerian Kesehatan RI. Available at: http://www.depkes. go.id/resources/download/general/Hasil\%20 Riskesdas\%2018.pdf.

2. 2.Harianto E, Pratomo H. Pajanan kebisingan dan hipertensi di kalangan pekerja pelabuhan. Jurnal Kesehatan Masyarakat Nasional 2013;8(5):21520. DOI: $10.21109 /$ kesmas.v8i5.387

3. 3.Souza TCF, Périssé ARS, Moura M. Noise exposure and hypertension : investigation of a silent relationship. BMC Public Health 2015; 15: 328. doi: $10.1186 / \mathrm{s} 12889-015-1671-\mathrm{z}$

4. 4.Sorensen M, Andersen ZJ, Nordsborg RB, et al. Long-term exposure to road traffic noise and incident diabetes: a cohort study. Environ Health Perspect 2013;121:217.doi:10.1289/ehp.1205503.

5. 5.Munzel T, Sorensen M. Noise pollution and arterial hypertension. ECR 2017;12. https://doi. org/10.15420/ecr.2016:31:2

6. 6.Chang TY, Liu CS, Huang HK, et al. Highfrequency hearing loss, occupational noise exposure and hypertension: a cross-sectional study in male workers. Environ Health 2011;10:35. doi:10.1186/1476-069X-10-35.

7. 7.Sherman BT, Galusha D, Cantley LF, et al. Occupational noise exposure and risk of hypertension in an industrial workforce. American journal of industrial medicine 2017;(August):1-8. https://doi.org/10.1002/ ajim. 22775

8. 8.Rhee CK, Lim SY, Yoo KH, et al. Comparison of world health organization and asia pacific body mass index classifications in COPD patient. Respirology 2017;22 (3):4-87. Doi:10.1111/ resp.13206

9. 9. Bell K, Twiggs J, Olin BR. Hypertension: The silent killer: Updated JNC8 Guideline recommendations. Continuing Education 2015. Alabama Pharmacy Association.

10. 10.Bodin T., Albin M, Ardö J, et al. Road Traffic noise and hypertension: results from a crosssectional public health survey in southern Sweden. Environ Health. 2011;8:38.doi: 10.1186/1476069X-8-38

11. 11.Chang TY,Hwang BF, Liu CS, etal. Occupational noise exposure and incident hypertension in men:
A prospective cohort study. American Journal of Epidemiology 2013;177 (8):818-25. doi: 10.1093/ aje/kws300. Epub 2013 Mar 6.

12. 12.Kalantary S, Dehghani A, Yekaninejad MS, et al. The effects of occupational noise on blood pressure and heart rate of workers in an automotive parts industry. ARYA Atheroscler 2015; 11(4): 215-9

13. 13.Tomei G, Fioravanti M, Cerratti D, et al. Occupational exposure to noise and the cardiovascular system: A meta-analysis. Science Total Environment 2009;408(4):681-9. DOI:10.1016/j.scitotenv.2009.10.071

14. 14.Skogstad M, Johannessen HA, Tynes T, et al. Systematic review of the cardiovascular effects of occupational noise. Occupational med 2016; 66(1):6-10. doi: 10.1093/occmed/kqv148.

15. 15.Rizi HAY, Dehghan H. Effects of occupational noise exposure on changes in blood pressure of workers. ARYA Atherosclerosis Journal 2012;8: 183-6.

16. 16.Nawaz KS, Hasnain S . Noise induced hypertension and prehypertension in Pakistan Bosn J Basic Med Sci. 2010;10(3):239-244. doi: 10.17305/bjbms.2010.2694

17. 17.Attarchi M, Golabadi M, Labbafinejad Y, et al. Combined effects of exposure to occupational noise and mixed organic solvents on blood pressure in car manufacturing company workers. Am J Ind Med 2012;56(2):243-51. doi:[Belum ada isinya?] 10.1002/ajim.22086

18. 18.Liu CS, Young LH, Yu TY, et al. Occupational noise frequencies and the incidence of hypertension in a retrospective cohort study 2016;184(2):120-8. doi: 10.1093/aje/kwv333. Epub 2016 Jul 1.

19. 19.Liu J, Xu M, Ding L, et al. Prevalence of hypertension and noise-induced hearing loss in Chinese coal miners. J Thorac Dis 2016;8(3):4229. doi: $10.21037 /$ jtd.2016.02.59

20. 20.Wang F, Song X, Li F, et al. Occupational noise exposure and hypertension : a case-control study. J Public Health Emerg 2018;2(30):1-7. doi: 10.21037/jphe.2018.12.01 